\title{
Comparative Analysis of Single Phase Cascaded H-Bridge Multilevel Inverter
}

\author{
Jainil K. Shah ${ }^{1}$, Manish S. Patel ${ }^{2}$ \\ P.G.Student, Electrical Engineering Department, U.V.P.C.E, Mehsana, Ganpat University, Gujarat, India ${ }^{1}$ \\ Assistant Professor, Electrical Engineering Department, U.V.P.C.E, Mehsana, Ganpat University, Gujarat, India ${ }^{1}$
}

\begin{abstract}
Total harmonic distortion (THD) is a term used to describe the net deviation of a nonlinear waveform from ideal sine waveform characteristics. Total harmonic distortion is the ratio between the RMS value of the harmonics and the RMS value of the fundamental. In multilevel Inverter As we try to increase the number of levels THD reduces. This paper contains different single phase multilevel inverter configuration. Different cascaded $\mathrm{H}$ bridge type of inverters are pointed out in this paper. Cascaded $\mathrm{H}$ bridge type multilevel inverters are built in MATLAB simulation and results are illustrated.
\end{abstract}

Keywords: Total Harmonic Distortion, Multilevel inverters, Cascaded H bridge.

\section{INTRODUCTION}

From last decades, the multilevel inverters have drawn tremendous attention in the field of high voltage and high power applications. In the researches on multilevel inverters, determination of their respective control strategies is the emerging topic. Modern power electronics based devices have put a great effect on the development of new powerful applications and industrial solutions. But at the same time, these advances have increased the harmonic problems in line currents, which make distortion in the voltage waveforms. Diode power rectifiers, thyristor converters and static VAR compensators (SVCs) are examples of power electronics applications.

The series connection of several bridges allows working with much higher voltages and the stepped voltage waveforms to eliminate the voltage stress in associated equipment, such as transformers. Moreover, the bridges of each converter work at a very low switching frequency which allows working with low speed semiconductors and low switching frequency losses.

Filters are used for compensation of contaminating load with small power factor and to feed the load during voltage dips. The multilevel inverters perform power conversion in multilevel voltage steps to obtain improved power quality, lower switching losses, better electromagnetic compatibility and higher voltage capability. Considering these advantages, multilevel inverters have been gaining considerable popularity in recent years.

Comparing conventional two level inverter systems with multilevel inverter systems has the advantages that the lower harmonic components on the output voltages can be eliminated and EMI problem could be decreased. Due to these merits, many researches on multilevel inverters have been performed at simulations and an idea of using multilevel inverter instead of conventional inverter is developed.

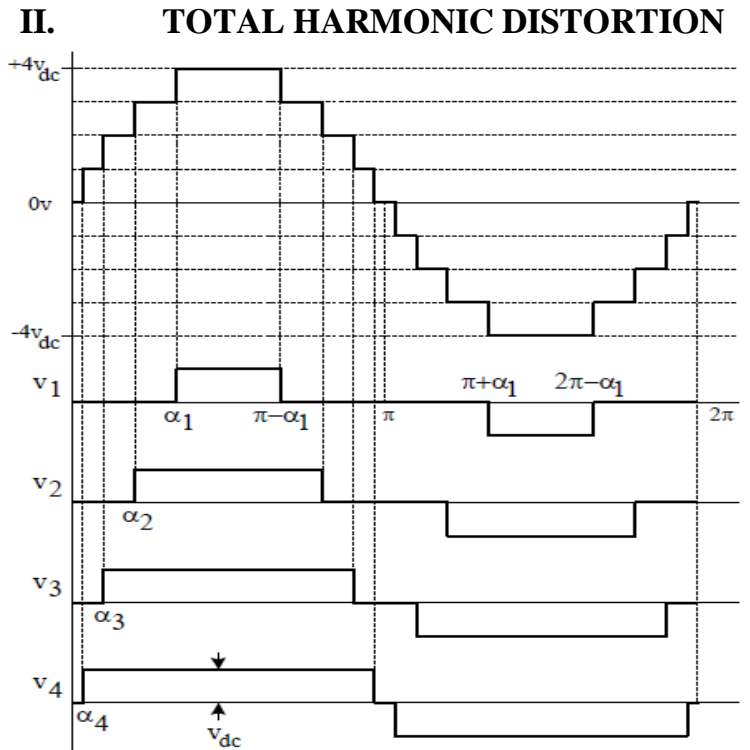

Figure 1 Levels in Multilevel Inverter

Total harmonic distortion (THD) is a term used to describe the net deviation of a nonlinear waveform from ideal sine waveform characteristics. Total harmonic distortion is the ratio between the RMS value of the harmonics and the RMS value of the fundamental.

$\mathrm{H}(\mathrm{n})=4 / \pi n[\cos n \alpha 1+\cos n \alpha 2+\cos n \alpha 3+\ldots+\cos n \alpha \mathrm{s}]$ $\mathrm{N}=1,3,5,7 \ldots$

The angles, $\alpha 1, \alpha 2, \alpha 3, \ldots, \alpha$, can be chosen such that the voltage total harmonic distortion is a minimum. Generally, these angles are chosen so that predominant lower frequency harmonics, 5th, 7th, 11th, and 13th, harmonics are eliminated.

$\mathrm{THD}=\frac{\sqrt{\sum_{h=3_{z} 5_{z} \mathrm{~F}_{m}}^{\infty} V_{h}^{2}}}{V_{1}} \times 100 \% \ldots \ldots \ldots .$. 
III.

\section{SINGLE PHASE MULTILEVEL INVERTERS}

Table 1. Comparison of conventional and multilevel inverter

\begin{tabular}{|c|c|c|}
\hline S.No. & $\begin{array}{l}\text { Conventional } \\
\text { Inverter }\end{array}$ & $\begin{array}{l}\text { Multilevel } \\
\text { Inverter }\end{array}$ \\
\hline 1 & $\begin{array}{l}\text { Higher voltage levels } \\
\text { are not produced }\end{array}$ & $\begin{array}{l}\text { Higher voltage } \\
\text { levels are } \\
\text { produced }\end{array}$ \\
\hline 2 & $\begin{array}{l}\text { Not applicable for } \\
\text { high voltage } \\
\text { applications }\end{array}$ & $\begin{array}{l}\text { applicable for } \\
\text { high voltage } \\
\text { applications }\end{array}$ \\
\hline 3 & $\begin{array}{c}\text { Higher switching } \\
\text { frequency is used } \\
\text { hence switching losses } \\
\text { is high }\end{array}$ & $\begin{array}{l}\text { Lower switching } \\
\text { frequency is } \\
\text { used hence } \\
\text { reduction in } \\
\text { switching losses }\end{array}$ \\
\hline 4 & $\begin{array}{l}\text { Higher THD in output } \\
\text { voltage }\end{array}$ & $\begin{array}{l}\text { Low THD in } \\
\text { output voltage }\end{array}$ \\
\hline
\end{tabular}

TABLE I gives comparison between conventional and multilevel inverter in which multilevel inverter is better than conventional inverter.

\section{A. Type of Multilevel Inverter}

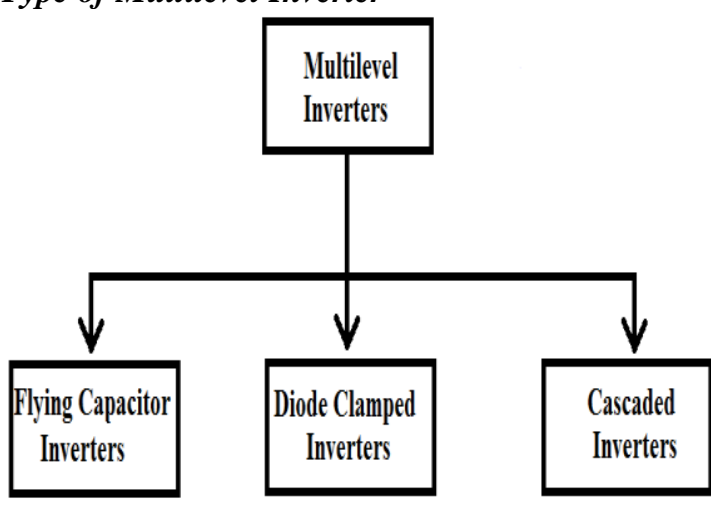

Figure 2 Classification of multilevel inverters

In fig. 2 different types of multilevel inverters are given. Each multilevel inverter contains different features and different control schemes and different structures in themselves. Multilevel inverter topologies are classified into three categories diode clamped inverters, flying capacitor inverters and cascaded inverters. In Diode clamped inverters clamping diodes per phase, DC bus capacitors, power semiconductor switches are presented. In flying capacitor inverters power semiconductor switches, DC bus capacitors, balancing capacitors per phase are presented. In cascaded inverters DC bus capacitors, power semiconductor switches are presented.

\section{Comparison of Multilevel Inverter Topologies}

$>$ Total Harmonic Distortion of output voltage.

$>$ Amplitude of fundamental and dominant harmonic components.

> Number of semiconductor devices used per phase leg.

$>$ Control complexity based on voltage unbalances and power switches.

$>$ Number of balancing capacitors used per phase leg.

$>$ Number of DC bus capacitors used.
Cascaded inverter requires the least number of components to achieve the same number of voltage levels in comparison with diode clamped and flying capacitor inverters. The implementation costs of the FCMLI and CMLI are almost same but it is fifteen percentages lower than that of DCMLI. It is found from above comparison that the cascaded multilevel inverter topology is the most promising one. Cascaded inverters provide a compounding of voltage levels leads to lower harmonic distortion avoids single isolated voltage sources and constructed with the low rating power devices which are commercially market ready.

\section{B. CASCADED H-BRIDGE MULTILEVEL (CHB) INVERTERS}

In the field of research of power electronics Multilevel inverters are producing more interest. Multilevel inverters are the most attractive technology for the medium to high voltage range, which includes power distribution, power quality. The general structure of the multilevel converter is to synthesize a near sinusoidal voltage from several levels of DC voltages. As more steps are added to the waveform, the harmonic distortion of the output wave decrease, approaching zero as the number of levels increases. A cascaded multilevel inverter consists of a series of $\mathrm{H}$ bridge inverter units. Series $\mathrm{H}$ bridge inverter appeared in 1975.

Among the different structures of multilevel inverter cascaded multilevel inverter is more preferable and popular. A cascade multilevel inverter consists of a series of H-bridge (single-phase full bridge) inverter units in each of its three phases. Each $\mathrm{H}$ bridge unit has its own dc source. Each SDCS (separate D.C. source) is associated with a single-phase full-bridge inverter. In this circuit, the number of voltage levels is defined by $m=(2 \mathrm{H}+1)$, where $\mathrm{H}$ is the number of $\mathrm{H}$-bridge cells per phase leg. The Neutral Point Clamped converters requires neutral point control and capacitor voltage balance. With the increase in the output voltage level, the requirement of the clamping diodes increases, the neutral point control and the power circuit become complex. The Flying capacitor converter balances voltage naturally but the capacitors has to be precharged. Although this converter is modular in structure, but requires large number of flying capacitors as the output voltage level increases and thus adds to the cost. In contrast to this, CHB converters have no voltage balancing problems due to separate DC sources. Its power rating can be increased by the series connection of the cells.

In $\mathrm{CHB}$ converter, each switching devices always conduct for half cycle, hence distributing the current stress equally among the switching devices. No clamping diodes present as in NPC and no voltage balancing capacitors present as in flying capacitor circuit. Separate DC sources eliminate the need of the voltage balancing circuits. It can work at reduced power level when one of its cell or SDCS is damaged. Soft switching techniques can be applied to CHB. The converter circuit is based on the series connection of single-phase inverters with separate dc 
sources. The resulting phase voltage is synthesized by the addition of the voltages generated by the different cells. In a 3-level cascaded inverter each single-phase full-bridge inverter generates three voltages at the output: $+\mathrm{Vdc}, 0$,$\mathrm{Vdc}$ (positive dc voltage, zero and negative dc voltage).

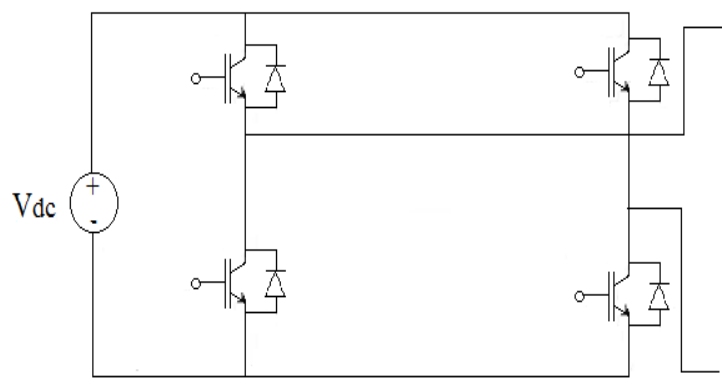

Figure 3 Single Phase 3 Level H bridge

This is made possible by connecting the capacitors sequentially to the ac side via the power switches. The resulting output ac voltage swings from $-\mathrm{Vdc}$ to $+\mathrm{Vdc}$ with three levels, $-2 \mathrm{Vdc}$ to $+2 \mathrm{Vdc}$ with five-level and $-3 \mathrm{Vdc}$ to $+3 \mathrm{Vdc}$ with seven-level inverter. The staircase waveform is nearly sinusoidal, even without filtering. The number of voltage levels ina $\mathrm{CHB}$ inverter can be found by following equation.

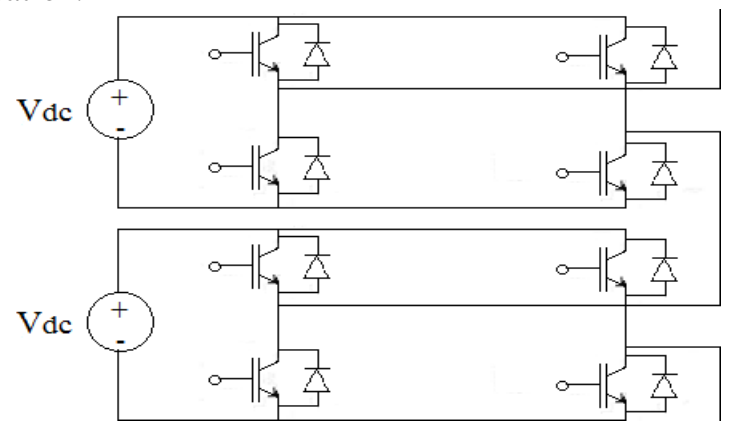

Figure 4 Single Phase 5 Level $\mathrm{H}$ bridge.

In equation (2) $\mathrm{m}$ is the number of level and $\mathrm{H}$ is the number of $\mathrm{H}$-Bridge.

$\mathrm{m}=(2 \mathrm{H}+1)$

the voltage level $\mathrm{m}$ is always an odd number for the $\mathrm{CHB}$ inverter. As shown in fig 4 is the five level structure of cascaded $\mathrm{H}$ bridge where two $\mathrm{H}$ bridge structure .

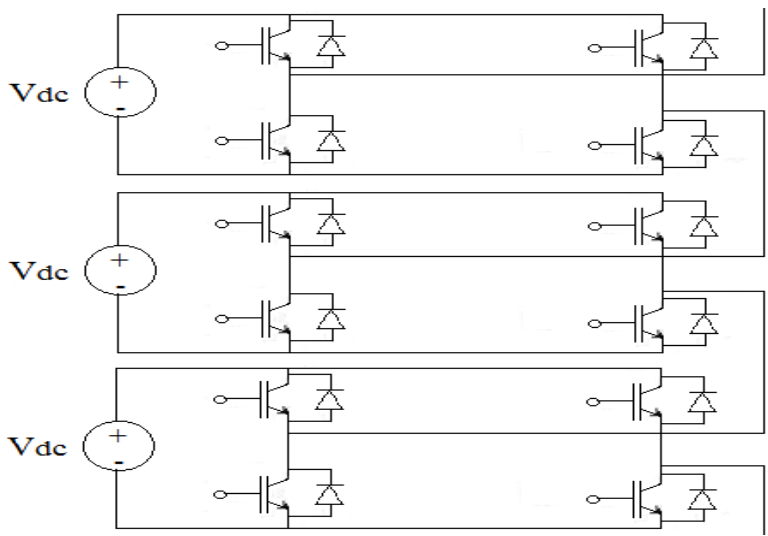

Figure 5 Single Phase 7 Level H bridge

In fig 5 is seven level structure of cascaded $\mathrm{H}$ bridge where three $\mathrm{H}$ bridge structure is given.

\section{SINGLE PHASE H BRIDGE MULTILEVEL INVERTERS}

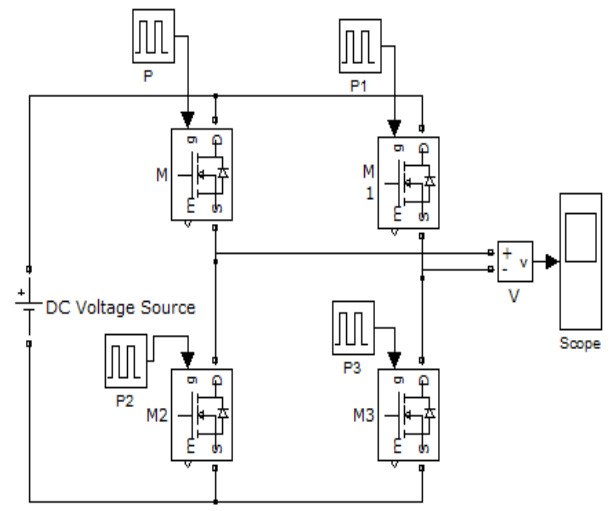

Figure 6 Three Level $\mathrm{H}$ bridge model in MATLAB

Figure 6 gives 3 level h bridge inverter in which 4 mosfet switches are used dc voltage source is of $400 \mathrm{v}$.

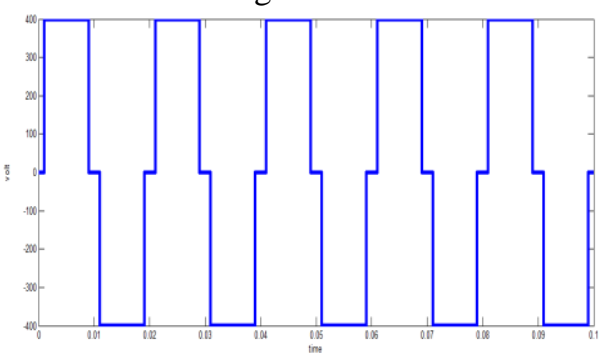

Figure 7 Output voltage waveform of Three Level $\mathrm{H}$ bridge model in MATLAB.

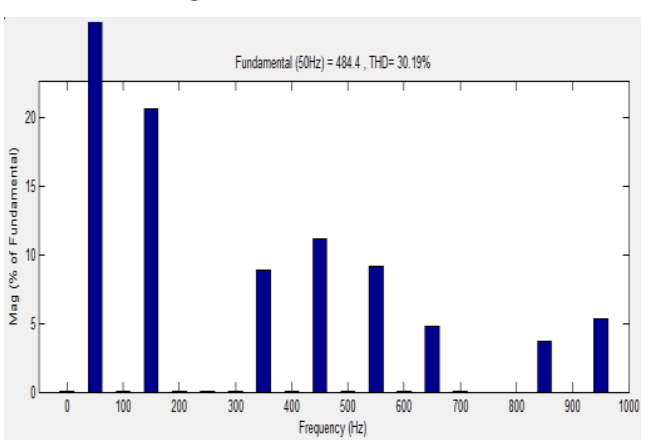

Figure 8 THD of Three Level $\mathrm{H}$ bridge model in MATLAB

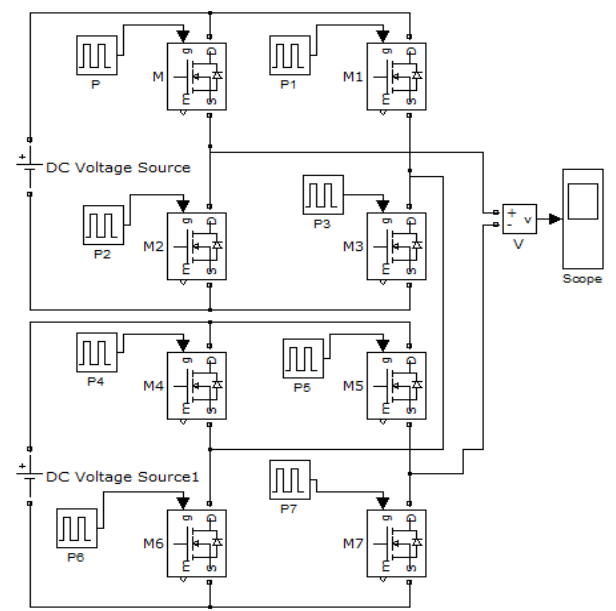

Figure 9 Five Level $\mathrm{H}$ bridge model in MATLAB 


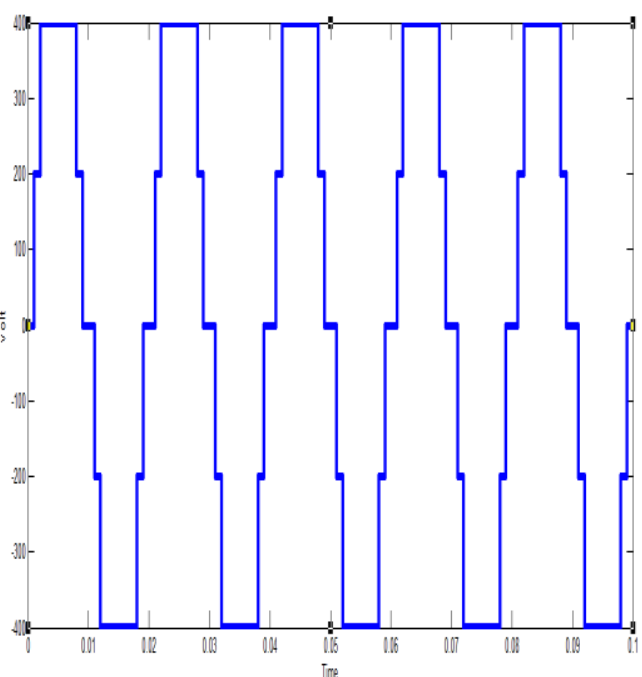

Figure 10 Output voltage waveform of Five Level $\mathrm{H}$ bridge model in MATLAB

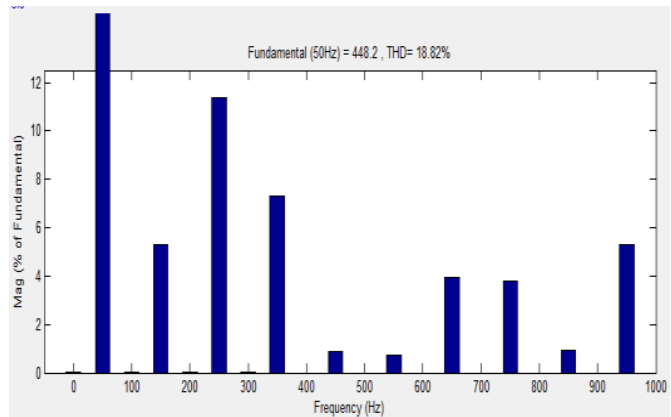

Figure 11 THD of Five Level $\mathrm{H}$ bridge model in MATLAB
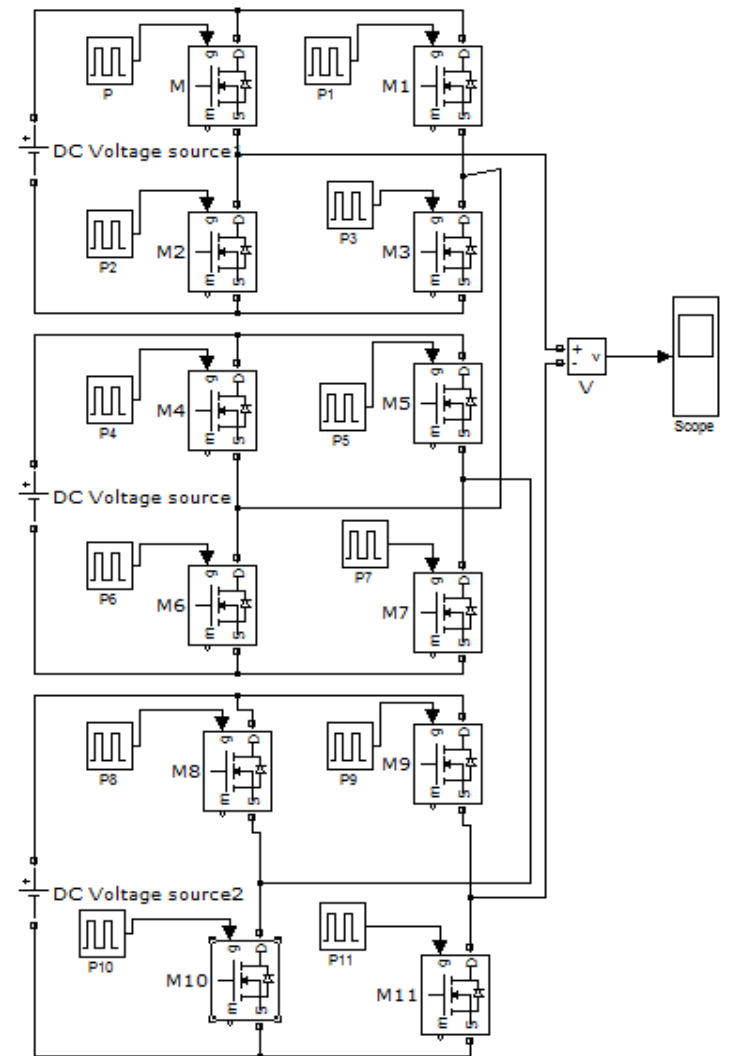

Figure 12 Seven Level H bridge model in MATLAB

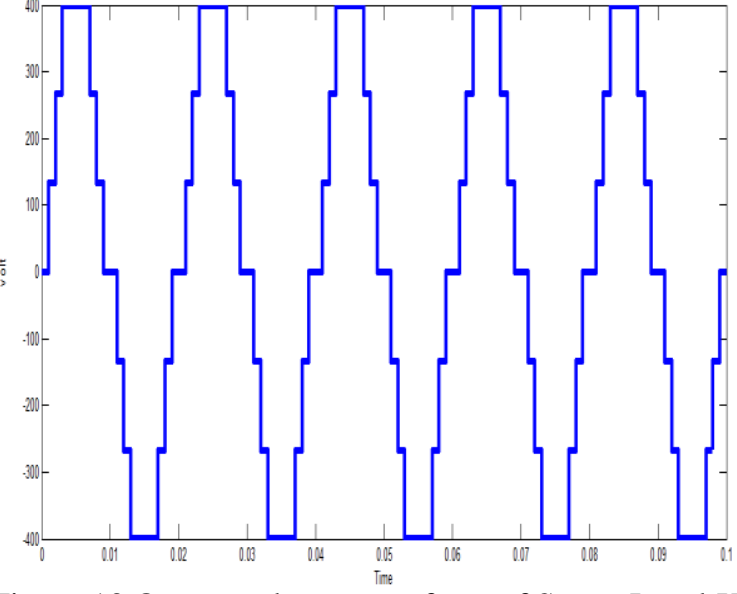

Figure 13 Output voltage waveform of Seven Level $\mathrm{H}$ bridge model in MATLAB

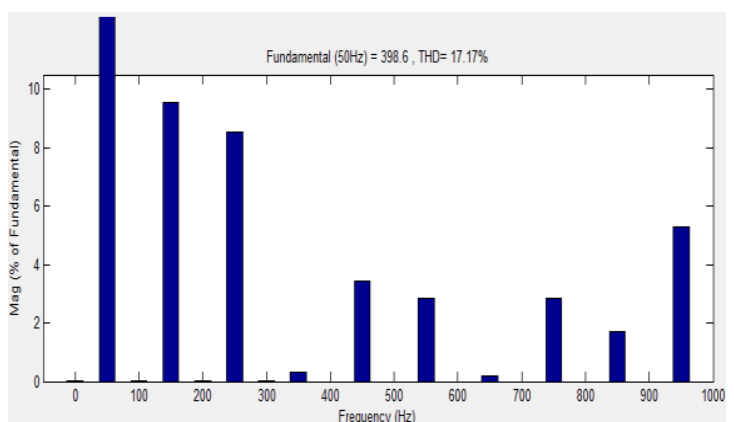

Figure 14 THD of Seven Level H bridge model in MATLAB

In this paper the comparison of THD for single Phase cascaded $\mathrm{H}$ bridge multilevel inverter starting from 3level to 7- level. Single phase cascaded H Bridge inverters are implemented in MATLAB/SIMULINK. A MOSFET is selected as a switch. The switches are triggered at regular intervals. The frequency of the output voltage is $50 \mathrm{~Hz}$.All above simulations are done at 0.1 simulation run time and $400 \mathrm{v}$ dc voltage source.

Table II. Comparison of thd of single phase cascaded $h$ bridge multilevel inverter

\begin{tabular}{|c|c|c|}
\hline Sr.no & Level & THD \\
\hline 1 & 3 & $30.19 \%$ \\
\hline 2 & 5 & $18.82 \%$ \\
\hline 3 & 7 & $17.17 \%$ \\
\hline
\end{tabular}

\section{CONCLUSION}

This paper presents the comparison of THD of 3, 5, 7 level single phase cascaded $\mathrm{H}$ bridge multilevel inverter. The results show that as the number of levels increases the THD reduced in single phase inverter. To generate the pulses lot of computations are required, as the switches are triggered at regular intervals. This can be avoided by applying the PWM techniques for multilevel inverters in future. THD can be further decreased by applying the PWM methods.

Single phase cascaded $\mathrm{h}$ bridge multilevel inverters are implemented on $400 \mathrm{~V}$ DC voltage source in MATLAB. 
Comparison of THD of 3, 5 and 7 level inverters are given in TABLE II. From the above comparison, we conclude that as per the number of levels in multilevel inverter increases THD decreases.

\section{REFERENCES}

[1] Lim Ziyou, Ali Maswood, "Seven-Level Reduced Flying Capacitor Inverter with Improved Harmonic Distortion using Hybrid PhaseShifted Carrier Phase-Disposition PWM", IEEE 2014.

[2] Hema Latha Javvaji, B.Basavaraja, "Simulation \& Analysis of Different Parameters of Various Levels of Cascaded H Bridge Multilevel Inverter",IEEE 2013.

[3] Jingsheng Liao, Keith Corzine, "A New Control Method for SingleDC-Source Cascaded H-Bridge Multilevel Converters Using PhaseShift Modulation", IEEE 2008.

[4] Eryong Guan, Pinggang Song, Manyuan Ye, "Selective Harmonic Elimination Techniques for Multilevel Cascaded H-Bridge Inverters", IEEE 2005.

[5] Hossein Sepahvand, Jingsheng Liao, Mehdi Ferdowsi, "Capacitor Voltage Regulation in Single-DC-Source Cascaded H-Bridge Multilevel Converters Using Phase-Shift Modulation”, IEEE 2012.

[6] Rajesh Ahuja, Lalit Aggarwal, Pankaj Kumar, "Simulation of Single Phase Multilevel Inverters with Simple control Strategy Using MATLAB”, IJAREEIE, Vol.2, 2013, pp.5190-5198.

[7] G. Mahesh Manivanna, S.Rama Reddy, "Analysis and Simulation of Seven Level Inverter System”, IJETS, Vol.1, 2010, pp.62-68.

[8] Amrita Tuteja, Dr.Amita Mahor, Aarti Sirsat, "A review on mitigation of Harmonics in cascaded $\mathrm{H}$ bridge Multilevel inverter using optimization techniques", IJETAE, Vol.3, 2013, pp.30-34.

[9] N. Chellammal, Subhransu Sekar Dash, "Power Quality Improvement Using Multilevel Inverter as Series Active Filter" ,IEEE 2012.

[10] K.N.V. Prasad, G.Ranjith kumar, "Realization of Cascaded H Bridge 5 Level MultilevelInverter as Dynamic Voltage Restorer", IEEE 2013

[11] AN Tiwari, KP Singh, Bipin Singh, "Comparative Analysis of 3Level \& 5-Level Inverter Controlled With DVR", GJCAT, Vol 2 (1), 2012, pp.865-869.

[12] S.Leela, S.S.Dash, "control of three level inverter based dynamic voltage restorer", Journal of Theoretical and Applied Information Technology 2005-2009, pp.13-17.

[13] MUHAMMAD H. RASHID“Power Electronics Handbook". 